\title{
Population Dynamics of the Sting Nematode in California Turfgrass
}

\author{
Sadia Bekal and J. Ole Becker, Department of Nematology, University of California, Riverside 92521
}

\begin{abstract}
Bekal, S., and Becker, J. O. 2000. Population dynamics of the sting nematode in California turfgrass. Plant Dis. 84:1081-1084.

Population densities of Belonolaimus longicaudatus were monitored at monthly intervals at the Tamarisk country club golf course (1993 to 1994) and at the Annenburg Estates and Desert Island golf courses (1998). All three courses are located at Rancho Mirage, Coachella Valley, CA. The bermuda grass in the sampling area typically exhibited chlorosis at the beginning of April when the sting nematode populations began to increase. At the Tamarisk golf course, population density peaked in October, with 1,000 nematodes per $100 \mathrm{~cm}^{3}$ of soil, but declined rapidly, with the lowest population density occurring in December with approximately 50 nematodes per 100 $\mathrm{cm}^{3}$ of soil. At the Annenburg Estates and Desert Island golf courses, the nematode population densities peaked in June and July but declined rapidly to less than half of that density, presumably because of $B$. longicaudatus-caused host decline. Soil temperature and fluctuation of nematode densities were significantly correlated at all locations. Nematode distribution was greatest in the top $15 \mathrm{~cm}$ of soil except during the hottest summer months, when the population was higher at depths of 15 to $30 \mathrm{~cm}$.
\end{abstract}

Additional keywords: nematode population density, plant parasitic nematode, soil temperature

The sting nematode, Belonolaimus longicaudatus, is an endemic parasite of the southern and midwestern United States $(13,14)$. It is recognized as the most damaging species of the genus Belonolaimus, affecting many plant species, including a wide range of economically important agricultural and horticultural crops $(5,13,14)$. Recently, B. longicaudatus was associated with chlorotic and dying turfgrass on several golf courses in the Coachella Valley, an inland desert in Southern California (12). The known distribution of the sting nematode in California is limited currently to 10 golf courses around Rancho Mirage. Turfgrasses in this arid area provide a suitable ecosystem for the sting nematode because it thrives in warm, sandy soil with frequent irrigation. The sting nematode population in this area has a high reproductive fitness and is able to parasitize a wide range of plants (1). This nematode is currently classified by the California Department of Food and Agriculture as an exotic pest and golf courses where sting nematodes were detected have been subjected to state- and county-enforced quarantine conditions.

Corresponding author: J. O. Becker

E-mail: ole.becker@ucr.edu

This research was supported by the University of California Integrated Pest Management Program.

Accepted for publication 15 June 2000.

Publication no. D-2000-0804-01R

(C) 2000 The American Phytopathological Society
Current strategies to reduce damage and restrict further spread of this pest in California are limited mainly to preplant soil fumigation or postplant applications of the nonfumigant nematicide phenamiphos. Further legislative restrictions on the use of traditional nematicides are expected; therefore, many so-called biorational or soft nematicides have appeared on the market. These products are, in general, thought to be more environmentally benign but often do not have lasting efficacy against plantparasitic nematodes. Understanding the population dynamics of $B$. longicaudatus in the turfgrass ecosystem should help to develop strategies for the optimal timing of these nematode management tools. Earlier sting nematode population studies were conducted on various turfgrasses and corn in the eastern United States $(6,11,15)$. The objective of this study was to monitor, at monthly intervals, the population fluctuations of the sting nematode in infested turfgrass under the climatic conditions of Southern California.

\section{MATERIALS AND METHODS}

The sting nematode population densities were monitored monthly in 1993 to 1994 at the Tamarisk country club (TM), and in 1998 at the Annenburg Estates golf course (AE) and the Desert Island country club (DI). All properties are located in the Coachella Valley, CA, with an average annual precipitation of approximately 7.5 $\mathrm{cm}$. The sampling sites were chosen on fairways where chlorotic and dying bermuda grass (Cynodon dactylon (L.) Pers. cv. Arizona common) was observed the previous year. Bermuda grass was grown at all locations during spring to fall. After dethatching within the first 2 weeks of October, the golf courses were overseeded with perennial rye grass (Lolium perenne L. cv. Derby/Regal, TM; Blackhawk/Laredo, DI; and Top Hat/Platinum, AE; all with endophytic fungi) for winter cover while the bermuda grass remained dormant. In April and May, as soil temperature increased, the rye grass declined while the bermuda grass started growing again. At all three sites, soils were classified as a

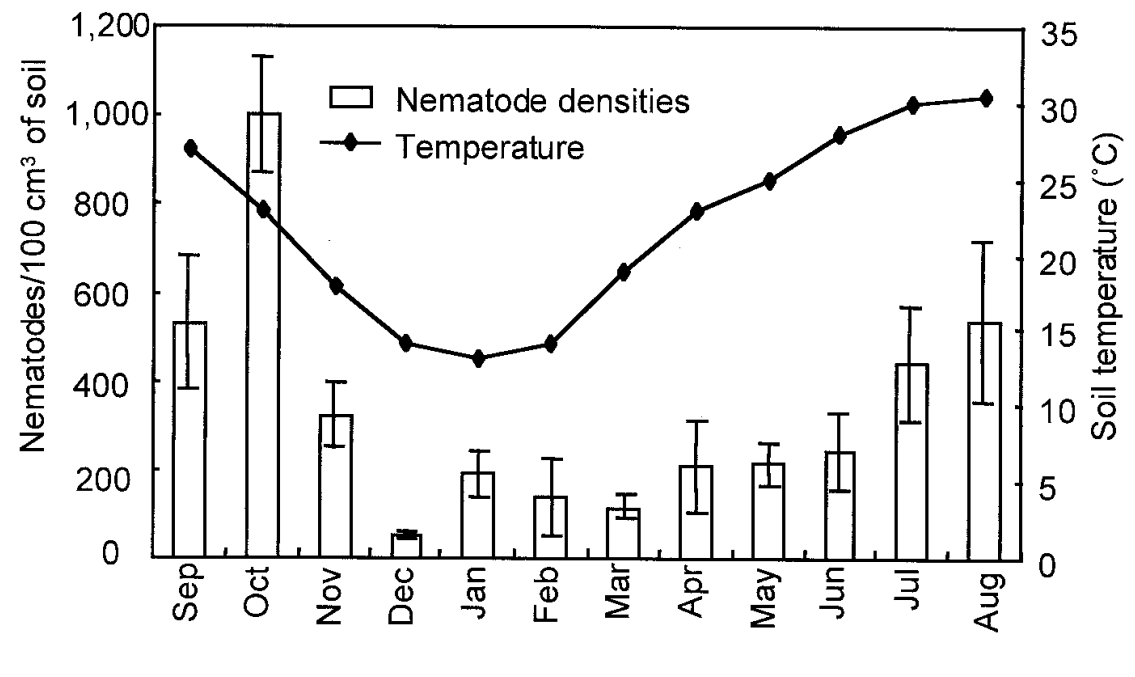

$1993 / 1994$

Fig. 1. Population density changes of Belonolaimus longicaudatus in relation to soil temperature at a depth of $15 \mathrm{~cm}$ at the Tamarisk country club. Values are means of all life-stages of the nematode \pm standard error at 0 - to $30-\mathrm{cm}$ soil depth. 
high, fine sand (>90\% sand) with $\mathrm{pH}$ of 7.2 to 7.6. Turfgrass in the fairways was fertilized with $11 \mathrm{~g}$ of $\mathrm{N}$ per square meter per year and mowed three times a week to a length of approximately $3 \mathrm{~cm}$. Irrigation was scheduled daily according to anticipated demand (evapotranspiration), typically at a rate of 2 to $6.5 \mathrm{~mm} /$ day during the dry season. Soil temperatures were obtained from meteorology stations of the California Irrigation Management Information System located at Indio, CA in 1993 to 1994 and at Thermal, CA in 1998, both located within $15 \mathrm{~km}$ of the sampling sites. At both stations, the temperature probes were placed $15 \mathrm{~cm}$ deep under irrigated common bermuda grass. In 1998, at each sampling date and at both locations, the soil temperature also was monitored at $15 \mathrm{~cm}$ of soil depth. At each sampling date and location, six soil cores $(1.9 \mathrm{~cm}$ in diameter) were taken at random from each of four areas. Samples were taken at TM at 0 to $15 \mathrm{~cm}$ of soil depth, and at AE and DI at 0 to 15 and 15 to $30 \mathrm{~cm}$. Soil cores at each location at each sampling date were pooled, mixed, and stored in cool boxes for transport to the University of California Nematode Quarantine Facilities, Riverside, CA. All samples were taken at the middle of each month. The October samples were obtained after overseeding.

Sting nematodes were extracted from $100-\mathrm{cm}^{3}$ subsamples using a combined sieving and sugar flotation method (10). Adults and juveniles were counted with the aid of an inverted stereomicroscope. Extraction efficiency was determined by adding known numbers of sting nematodes to four separate $100-\mathrm{cm}^{3}$ autoclaved

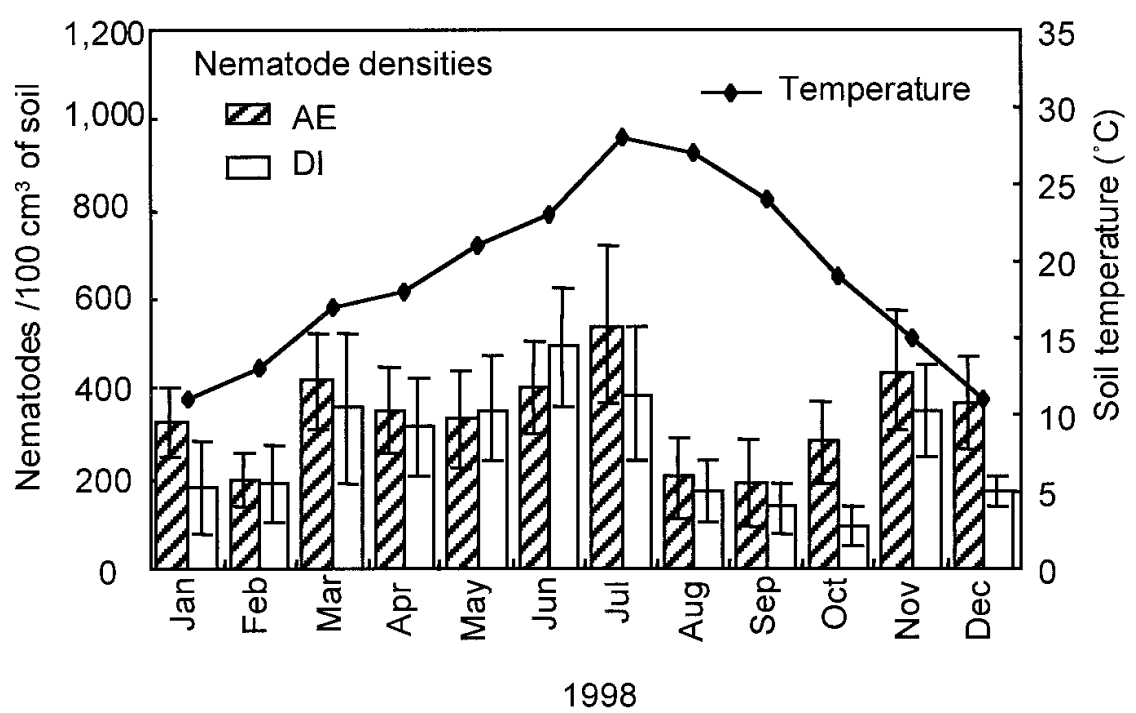

Fig. 2. Population density changes of Belonolaimus longicaudatus in relation to soil temperature at a depth of $15 \mathrm{~cm}$ at the Annenburg Estates golf course (AE) and Desert Island country club (DI). Values are means of all life-stages of the nematode \pm standard error at 30-cm soil depth.

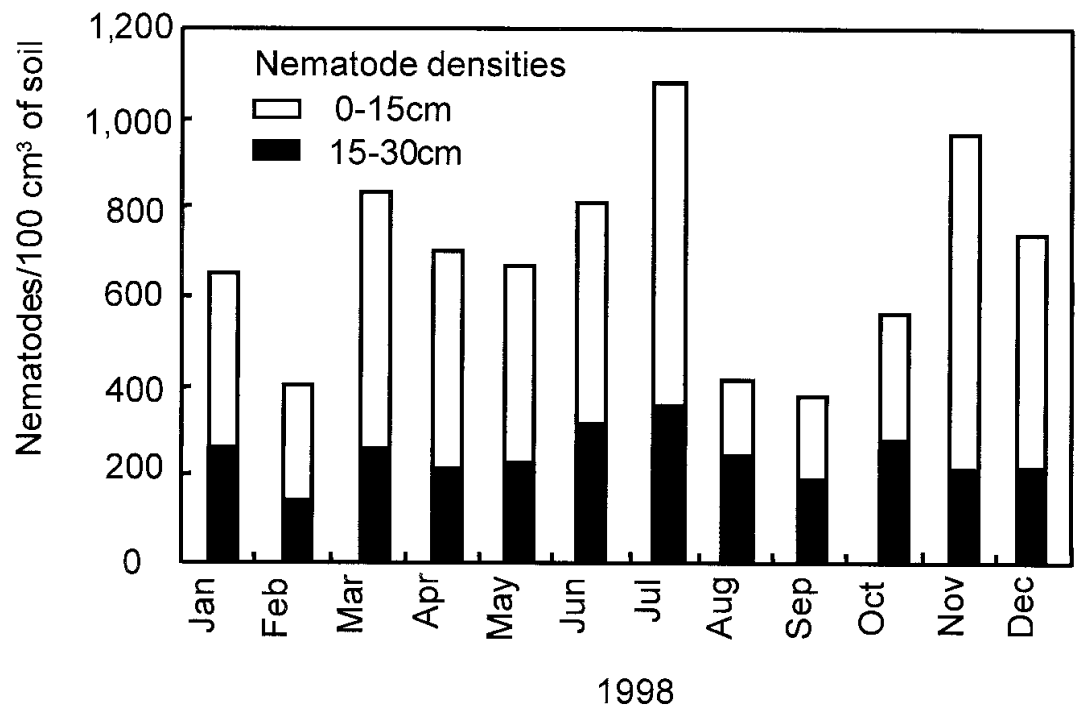

Fig. 3. Population density changes and soil depth distribution of Belonolaimus longicaudatus at the Annenburg Estates golf course. Values are means of total nematode life-stages in each soil depth.
TM soil samples and calculating the percentage recovered. Extraction efficiency was significantly higher $(P<0.05)$ for adults $(40 \%)$ than juveniles $(34 \%)$. However, the reported population densities were the actual numbers of recovered nematodes. The relationship between the sting nematode population density and soil temperature was assessed by regression analyses.

\section{RESULTS AND DISCUSSION}

The sting nematode population dynamics were similar at the three locations and were correlated to soil temperature. During 1993 to 1994 , the highest population density at TM occurred in October, with approximately 1,000 nematodes per $100 \mathrm{~cm}^{3}$ of soil (Fig. 1). Following dethatching and overseeding in early October with the cool season rye grass, the population density declined to less than a third between October and November. The lowest population density was in December and then gradually increased from spring to fall (Fig. 1). Although severe sting nematode-caused disease symptoms, such as chlorosis, growth depression, poor stand, and eventually browning of the foliage, were observed within the sampling area, grass cover remained sufficient to obtain soil samples with abundant roots during the entire sampling period. Overall, the population dynamics of $B$. longicaudatus was correlated to soil temperature $\left(r^{2}=0.40, P\right.$ $\leq 0.05$ ).

The sting nematode population dynamics at $\mathrm{AE}$ and DI were very similar $\left(r^{2}=\right.$ $0.73, P \leq 0.05)$ and were correlated for most of the year to the soil temperature (Fig. 2). The impact of temperature on the sting nematode population dynamics during October to August was higher for the DI population $\left(r^{2}=0.68, P \leq 0.05\right)$ compared with AE population $\left(r^{2}=0.44, P \leq\right.$ 0.05 ). Population densities ranged from approximately 140 to 520 sting nematodes throughout the sampling period. Significant population increases did not occur until the soil temperature reached $20^{\circ} \mathrm{C}$, which coincided with recovery of the bermuda grass in spring. Populations at both $\mathrm{AE}$ and DI peaked in June to July, compared to October at TM. However, at both $\mathrm{AE}$ and DI, damage to the bermuda grass by the sting nematode became so severe in July that large patches of grass died and, consequently, soil samples contained very few roots. The subsequent decline of the nematode population in August probably was due to a limited food supply. The data at TM showed that, in relatively undamaged turfgrass sites, the sting nematode population density can reach up to 1,000 individuals per $100 \mathrm{~cm}^{3}$ of soil. Under a susceptible St. Augustine grass in Florida, the population density of $B$. longicaudatus peaked at 856 nematodes per $100 \mathrm{~cm}^{3}$ after only 84 days following pot inoculation (6). 
Sting nematode densities were high in the top $15 \mathrm{~cm}$ of soil for both $\mathrm{AE}$ and DI (Figs. 3 and 4) during most of the year, except from mid-August to mid-October, when populations were greater at a depth of 15 to $30 \mathrm{~cm}$. The temperature in the top layer of the bare soil might have caused the sting nematodes to migrate to deeper depths, a behavior similar to that of $B$. longicaudatus in corn and forage grasses $(2,13)$. Growth of rye grass after overseeding in October provided young roots with new feeding sites for the nematodes and, consequently, resulted in a population buildup. This contrasts with observations from Florida where overseeding with rye grass did not affected various populations of plant-parasitic nematodes, including $B$. longicaudatus (7). However, differences in soil temperatures between the Florida and California studies are likely to be the discriminating factor. In the Florida study, soil temperatures at $5 \mathrm{~cm}$ in the first 46 days of the experiment were about $21^{\circ} \mathrm{C}$, which is marginal for the sting nematode to develop and reproduce (9). In the Coachella Valley, soil temperature at $15 \mathrm{~cm}$ averaged $23^{\circ} \mathrm{C}$ in October 1993 and close to $20^{\circ} \mathrm{C}$ in October 1998. This would indicate that the temperature in the shallow root zone of rye grass seedlings was well within the suitable range for a sting nematode build up. Fluctuation in the number of juveniles at both $\mathrm{AE}$ and DI showed a time series of peaks (Figs. 5 and 6), which perhaps represent three-generation cycles. Previous in vitro studies demonstrated that, at $28^{\circ} \mathrm{C}$, the life cycle of the sting nematode was completed in 24 days (9).

Differences in the range between minimal and maximal population densities were higher for the TM population than for $\mathrm{AE}$ and DI. This might be attributed to the variations in turf management conditions and soil ecosystems at the various locations. Despite differences in climate, these data are similar to those reported from a two-year study of $B$. longicaudatus dynamics of a North Carolina population (11).

The strategy to manage the sting nematode in California is primarily to isolate and quarantine infested areas, thereby limiting their spread. The proximity of homes and public places around the infested golf courses practically excludes the use of preplant fumigation. So far, no turfgrass has shown acceptable resistance or tolerance to this nematode, although differences in sensitivity to sting nematode parasitism have been reported with St. Augustine grasses $(3,4)$ and bermuda grasses $(8)$. The best time for optimizing the use of postplant nematicides and biorationals is perhaps in fall, when the population density of the sting nematode is often so high that the establishment of the winter cover is difficult. Also, application prior to spring greenup may help to protect the young bermuda grass roots against an early attack

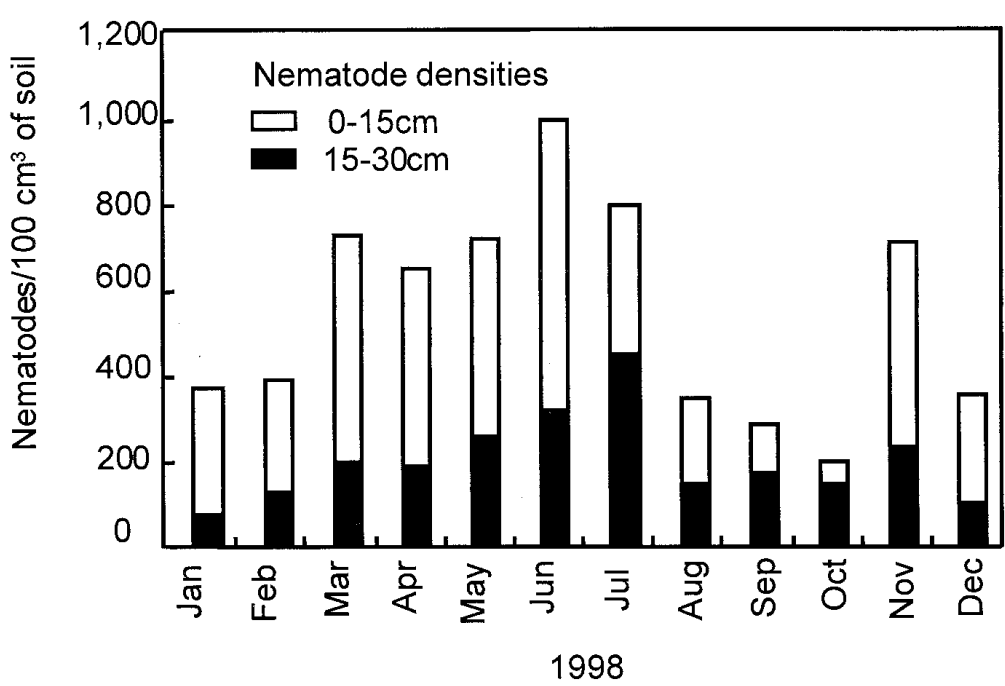

Fig. 4. Population density changes in adults and juveniles of Belonolaimus longicaudatus at the Desert Island country club. Values are means of total nematode life-stages in each soil depth.

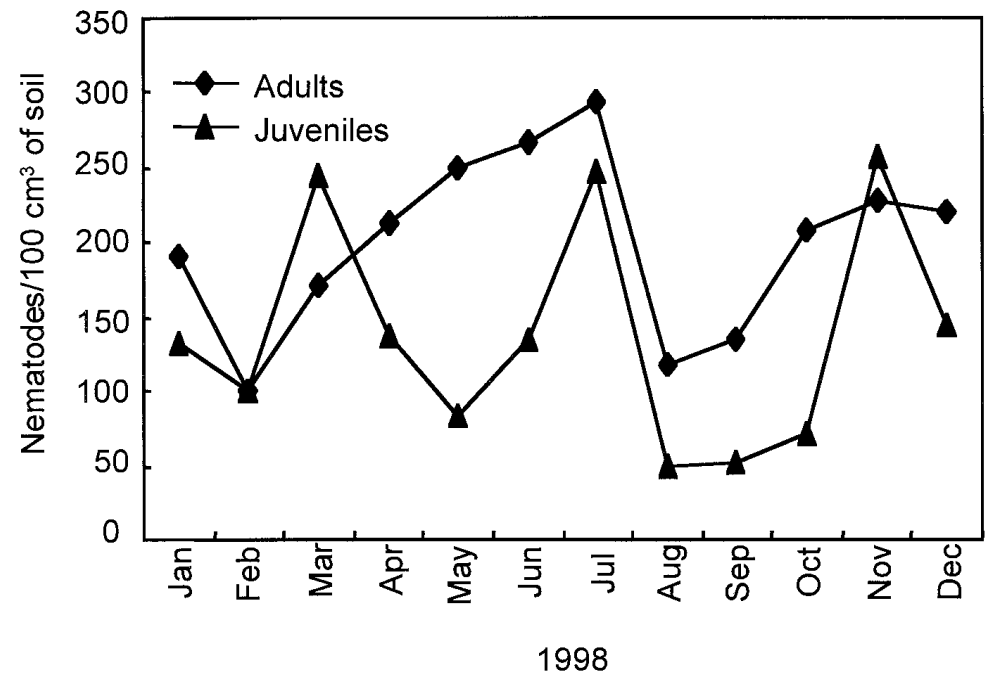

Fig. 5. Population density changes of adults and juveniles of Belonolaimus longicaudatus at the Annenburg Estates golf course. Values are means of adults (males and females) and juveniles (J2 + $\mathrm{J} 3+\mathrm{J} 4$ ) within the 0 - to $30-\mathrm{cm}$ soil depth.

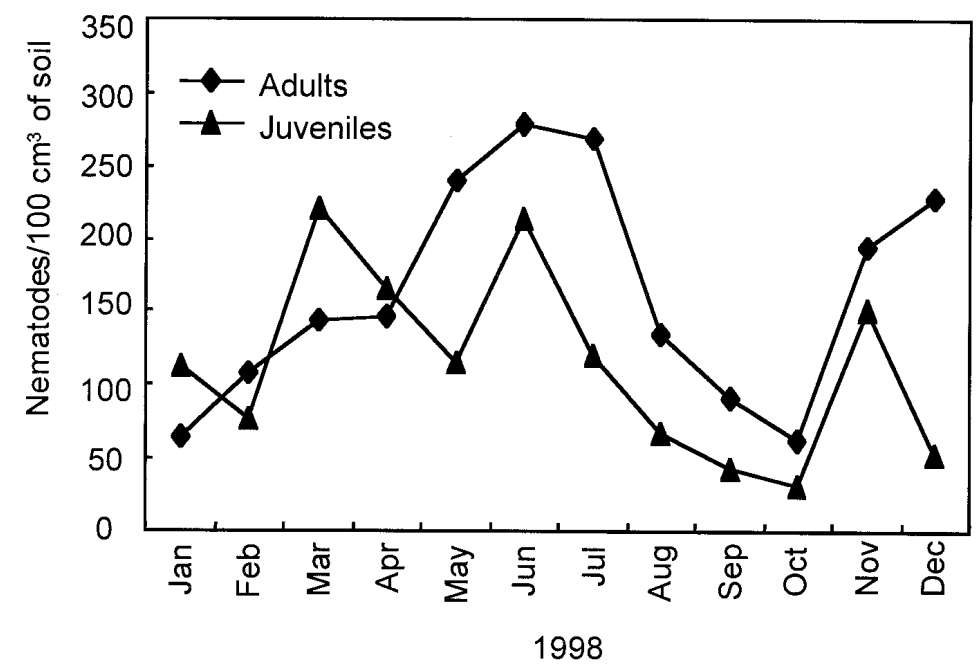

Fig. 6. Population density changes of adults and juveniles of Belonolaimus longicaudatus at the Desert Island country club. Values are means of adults (males and females) and juveniles $(\mathrm{J} 2+\mathrm{J} 3+$ J4) within the 0- to 30-cm soil depth. 
by the sting nematodes. Even short-term efficacy might be of special value in fall because, by mid-November, the soil temperature is typically too low to sustain much activity of this nematode. As demonstrated in this study, the nematode population density does not increase significantly until late spring. Fortunately for golfers and the associated industries, this period of low sting nematode population densities, and consequently healthy turf, coincides with the main golf season in the Coachella Valley.

\section{ACKNOWLEDGMENTS}

We thank John Darsow for technical assistance and the superintendents of the participating golf courses, J. Lindblad, R. Sall, and V. Davila, for help during sampling.

\section{LITERATURE CITED}

1. Bekal, S., and Becker, J. O. 1998. Host reactions to the California population of the sting nematode Belonolaimus longicaudatus. (Abstr.) Phytopathology 88:S7.

2. Boyd, F. T., and Perry, V. G. 1971. Effects of seasonal temperatures and certain cultural treatments on sting nematodes in forage grass.
Proc. Soil Crop Sci. Soc. Fla. 30:360-65

3. Busey, P., Giblin-Davis, R. M., and Center, B. J. 1993. Resistance in Stenotaphrum to the sting nematode. Crop Sci. 33:1066-1070.

4. Busey, P., Giblin-Davis, R. M., Riger, C. W., and Zenker, E. I. 1991. Susceptibility of diploid St. Augustinegrasses to Belonolaimus longicaudatus. Suppl. J. Nematol. 23:604610.

5. Esser, R. P. 1976. Sting nematodes, devastating parasites of Florida crops. Fla. Dep. Agric. Consumer Serv. Div. Plant Ind. Gainesville. Nematol. Circ. 18.

6. Giblin-Davis, R. M., Busey, P., and Center, B. J. 1992. Dynamics of Belonolaimus longicaudatus parasitism on a susceptible St. Augustinegrass host. Suppl. J. Nematol. 24:432-437.

7. Giblin-Davis, R. M., Cisar, J. L., Bilz, F. G., and Williams, K. E. 1991. Management practices affecting phytoparasitic nematodes in 'Tifgreen' bermudagrass. Nematropica 21:59-69.

8. Giblin-Davis, R. M., Cisar, J. L., Bilz, F. G., and Williams, K. E. 1992. Host status of different bermudagrasses (Cynodon spp.) for the sting nematode, Belonolaimus longicaudatus. Suppl. J. Nematol. 24:749-756.

9. Huang, X., and Becker, J. O. 1999. Life cycle and mating behavior of Belonolaimus longi- caudatus in gnotobiotic culture. J. Nematol. 31:70-74.

10. Jenkins, W. R. 1964. A rapid centrifugalflotation technique for separating nematodes from soil. Plant Dis. Rep. 48:692.

11. Lucas, L. T. 1982. Population dynamics of Belonolaimus longicaudatus and Criconemella ornata and growth response of bermudagrass and overseeded greens following treatment with nematicides. J. Nematol. 14:358-364.

12. Mundo-Ocampo, M. J., Becker, J. O., and Baldwin, J. 1994. Occurrence of Belonolaimus longicaudatus on bermudagrass in the Coachella Valley. Plant Dis. 78:529.

13. Perry, V. G., and Rhoades, H. L. 1982. The genus Belonolaimus. Pages 144-149 in: Nematology in the Southern Region of the United States. R. D. Riggs, ed. South. Coop. Ser. Bull. 276. Univ. Arkansas Agric. Publ. Fayetteville.

14. Smart, G. C., and Nguyen, K. B. 1991. Sting and awl nematodes: Belonolaimus spp. and Dolichodorus spp. Pages 627-667 in: Manual of Agricultural Nematology. W. R. Nickle, ed. Marcel Dekker, Inc., New York.

15. Todd, T. C. 1989. Population dynamics and damage potential of Belonolaimus sp. on corn. Suppl. J. Nematol. 21:697-702. 